\title{
THE EFFECT OF HYDROCORTISONE AND OF PIROMEN IN VITRO ON LEUKOCYTES OF PATIENTS RECEIVING ACTH AND CORTISONE THERAPY ${ }^{1}$
}

\author{
BY GRACE P. KERBY AND JOHN A. BARRETT, JR. \\ (From the Department of Medicine, Duke University School of Medicine, Durham, N. C.)
}

(Submitted for publication October 23, 1953; accepted January 6, 1954)

The relationship of adrenocorticosteroid hormones to the processes of infection, inflammation and repair have been reviewed by several authors, including Duke-Elder and Ashton (1), Rebuck and Mellinger (2), and Thomas (3). Selye (4) has described the overall effect produced in his experiments as an inhibition of development of granulomatous barriers between irritants and tissues. Opinions vary as to how alterations in the response of tissues are induced by the adrenocorticosteroids. Speculation on the basis of data accumulated thus far has dealt particularly with the question of the relative importance of indirect vascular effects and of more direct metabolic effects upon the leukocytes and the connective tissue elements involved in the reaction. Prevention of increased capillary permeability (5), slight increase in arteriolar tone (6), prevention of damage to the endothelium of arterioles and venules (7) and delay of growth of capillary loops $(8,9)$ have all been observed as vascular effects possibly contributing to the decreased cellular response at the site of injury. There have been numerous attempts made both in vivo and in vitro to dissociate the direct cellular reaction from vascular and other influences. Shapiro, Taylor, and Taubenhaus (10), for instance, noted the persistence of inhibition of formation of granulation tissue in animals treated with cortisone despite the fact that the site of injury had been denervated and made moderately ischemic. However, Steen (11) was unable to demonstrate any inhibition of fibroblastic growth by cortisone in chick embryonic tissue cultures when the cortisone level approximated the usual human therapeutic range. Gerarde and Jones (12) observed inhibition of fibroblasts in tissue culture only when

\footnotetext{
1 This investigation was supported by research grants from the National Microbiological Institute of the $\mathrm{Na}$ tional Institutes of the Public Health Service (E-520), the Duke University Research Council and the Baxter Laboratories, Inc.
}

the embryo from which the tissue was later obtained had been treated in vivo with cortisone. The conflicting observations in vivo and in vitro suggest that cellular alteration may take place in vivo, perhaps by indirect means, but that this alteration may persist in vitro, once established, at least in embryonic tissues. However, there are other indications (as in the work of Martin, Chaudhuri, Green, and McKinney [13], possibly Huisman [14], and Layton [15] ) that alteration of cellular metabolism can be induced by the action of cortisone, entirely in vitro.

The present work was undertaken to determine if a direct cellular alteration is demonstrable in man during ACTH or cortisone therapy and if the change persists when the tissue is removed from homeostatic influences to an environment in vitro. Leukocytes were studied, because these cells are readily and repeatedly available and they play a role in the general response of the body to injury. As an index to cellular injury, the release of an enzyme (lysozyme) from the cell was quantitated by measuring the amount of lysozyme appearing in the suspending medium under test conditions, and the effect of ACTH and cortisone upon this response of the leukocyte to injury was determined.

\section{METHODS}

Subjects. Control patients were individuals not roceiving adrenocorticosteroid therapy. They were a heterogeneous group otherwise, ranging from patients with no evidence of organic disease to seriously ill individuals, some of whom were subsequently treated with adrenocorticosteroids. Patients with diabetes mellitus or primary blood dyscrasias affecting leukocytes were excluded from the study.

Test patients were individuals receiving intravenous ACTH or oral cortisone in the course of therapy of various diseases. These included scleroderma, disseminated lupus erythematosus, cranial arteritis, sarcoidosis, optic neuritis, ulcerative colitis, asthma, pemphigus, thrombocytopenic and non-thrombocytopenic purpura, and nephrosis. Although serial observations were made in most 
TABLE I

Comparison of the in vitro release of lysosyme from leukocytes of untreated patients and patients receiving $A C T H$ or cortisone therapy

\begin{tabular}{|c|c|c|c|c|c|}
\hline \multirow[b]{2}{*}{ Patients } & \multirow{3}{*}{$\begin{array}{r}\begin{array}{c}\text { No. of } \\
\text { pts. }\end{array} \\
26 \\
8\end{array}$} & \multicolumn{4}{|c|}{$\begin{array}{l}\text { Per cent ( }+ \text { S.D.) lysis* of lysozyme substrate by } \\
\text { leukocytes exposed in vitro to: }\end{array}$} \\
\hline & & Saline & Piromen & Hydrocortisone & $\begin{array}{l}\text { Hydrocortisone } \\
+ \text { Piromen }\end{array}$ \\
\hline $\begin{array}{l}\text { A. Controls (no steroid Rx) } \\
\text { On i.v. ACTH } \\
\text { Comparison of }\{t \\
\text { corrected values }\left\{\begin{array}{l}\mathrm{p} \\
\end{array}\right.\end{array}$ & & $\begin{array}{c}23.6 \pm 9.8 \\
10.1 \pm 5.5 \\
3.702 \\
<0.01\end{array}$ & $\begin{array}{c}40.4 \pm 11.4 \\
18.0 \pm 9.2 \\
5.047 \\
<0.01\end{array}$ & $\begin{array}{c}16.8 \pm 8.0 \\
8.1 \pm 4.7 \\
2.729 \\
<0.01\end{array}$ & $\begin{array}{c}29.5 \pm 11.3 \\
14.0 \pm 7.5 \\
3.767 \\
<0.01\end{array}$ \\
\hline $\begin{array}{l}\text { B. Before } R x \\
\text { On high-dosage cortisone } \\
\text { Comparison of }\{t \\
\text { corrected values }\{p\end{array}$ & $\begin{array}{l}8 \\
8\end{array}$ & $\begin{array}{c}26.1 \pm 6.4 \\
15.3 \pm 4.0 \\
4.039 \\
<0.01\end{array}$ & $\begin{array}{c}40.3 \pm 8.0 \\
23.6 \pm 6.1 \\
4.709 \\
<0.01\end{array}$ & $\begin{array}{c}19.6 \pm 4.9 \\
13.0 \pm 3.5 \\
3.115 \\
<0.01\end{array}$ & $\begin{array}{c}30.3 \pm 6.5 \\
16.5 \pm 5.7 \\
4.526 \\
<0.01\end{array}$ \\
\hline $\begin{array}{l}\text { C. Controls (no steroid Rx) } \\
\text { On maintenance cortisone } \\
\text { Comparison of }\left\{\begin{array}{l}t \\
\text { corrected values }\end{array}\right.\end{array}$ & $\begin{array}{r}26 \\
7\end{array}$ & $\begin{array}{c}23.6 \pm 9.8 \\
20.5 \pm 7.1 \\
0.788 \\
>0.05\end{array}$ & $\begin{array}{c}40.4 \pm 11.4 \\
37.1 \pm 10.0 \\
0.680 \\
>0.05\end{array}$ & $\begin{array}{c}16.8 \pm 8.0 \\
14.8 \pm 8.3 \\
0.539 \\
>0.05\end{array}$ & $\begin{array}{c}29.5 \pm 11.3 \\
26.5 \pm 11.7 \\
0.605 \\
>0.05\end{array}$ \\
\hline
\end{tabular}

* Corrected for plasma residue (see Text, Experimental Procedure).

of the patients, the data presented here are those obtained after five days or more of ACTH (20 units given intravenously over 18 hours) or seven to nine days of highdosage (300 mg. per day) oral cortisone. ${ }^{2}$ Patients on maintenance cortisone had been receiving 50 to $100 \mathrm{mg}$. of the drug per day for at least 12 days and in most instances for more than one month.

In the high-dosage oral cortisone group, it was possible to obtain at least two baseline observations on each patient prior to therapy, so that in this group the patients served as their own controls. In the ACTH and maintenance cortisone groups, baseline studies were not uniformily possible, and comparisons were made with the control group already described.

Experimental procedure. Dextran-sedimented leukocytes prepared by a method previously described (16) were resuspended in a buffered balanced physiologic salt solution $^{8}$ containing $186 \mathrm{mg}$. per cent of dextrose to a final count of 11,000 leukocytes per $\mathrm{cmm}$. Three and twotenths $\mathrm{ml}$. of leukocyte suspension were added to an equal volume of (a) the balanced salt solution, or (b) the same, containing 30 micrograms per $\mathrm{ml}$. of either cortisone or hydrocortisone, free alcohol, Merck, giving a final count of 5,500 leukocytes per cmm. and a concentration of 15 micrograms of steroid per $\mathrm{ml}$. The mixtures were incubated in $25 \mathrm{ml}$. sterile siliconed flasks at $37^{\circ} \mathrm{C}$. in a Warburg shaker for three hours, at which time $2.8 \mathrm{ml}$.

2 The cortisone and hydrocortisone preparations used in this study were made available through the courtesy of Dr. Elmer Alpert of Merck and Co., Inc.

3 Ten ml. stock solution ( 7.5 per cent $\mathrm{NaCl}, 0.75$ per cent $\mathrm{KCl}, 0.1$ per cent $\mathrm{Na}_{2} \mathrm{HPO}_{4}, 0.12$ per cent $\mathrm{KH}_{2} \mathrm{PO}_{4}$, 0.05 per cent $\mathrm{K}_{2} \mathrm{HPO}_{4}$ ) and $7 \mathrm{ml}$. 1 per cent $\mathrm{Na}_{2} \mathrm{HPO}_{4}$ per $100 \mathrm{ml}$., aqueous.

4 The majority of the observations were made using in vitro hydrocortisone. When cortisone was used, the initial incubation period was four hours. of the contents of each flask were added to fresh flasks containing $0.7 \mathrm{ml}$. of (a) the glucose-fortified balanced salt solution or (b) the same containing PS Piromen, 520 micrograms per $\mathrm{ml}$. (to final concentration, therefore, of 4 micrograms of Piromen per ml.). The flasks were then incubated for an additional two hours, after which lysozyme titres were determined by a method previously described (16). In brief, $1.0 \mathrm{ml}$. of the test suspension was added to $1.5 \mathrm{ml}$. of lysozyme substrate, 6 and readings were obtained at zero time and at 20 minutes at $540 \mathrm{~m} \mu$ in a Coleman Junior Spectrophotometer, the blank containing 1.0 $\mathrm{ml}$. of the test suspension and $1.5 \mathrm{ml}$. of buffer. Per cent lysis of the substrate was calculated by the formula: $100-\left(\frac{\text { O.D.20 }}{\text { O.D. }}\right)$, where O.D.o and O.D.20 represent the optical densities at zero time and at 20 minutes, respectively. An increased lysozyme titre on in vitro exposure of leukocytes to various agents (as compared to the titre observed in a sample of the same leukocyte suspension not so exposed but otherwise identically handled) was interpreted as evidence of at least one type of leukocyte damage. ${ }^{7}$ A decreased lysozyme titre on in vitro ex-

5 A bacterial polysaccharide derived from Pseudomonas aeruginosa and supplied through the courtesy of Dr. L. G. Ginger of Baxter Laboratories, Inc.

- A dried preparation of M. lysodeikticus, obtained commercially as Bacto Lysozyme Substrate and prepared for use as previously described (16).

7 Under conditions known to produce cellular injury, e.g., a step-wise decrease in salt concentration of the suspending medium, there occurs a step-wise increase in the amount of lysozyme appearing extracellularly for titration. Similarly, the exposure of human leukocytes to an antiserum to human leukocytes or to various damaging bacterial derivatives results in the release of increased amounts of lysozyme into the suspending medium where it can be measured. On the basis of these observations 
TABLE II

Comparison of the in vitro lysozyme activity of leukocyte lysates and plasma of untreated patients and patients receiving $A C T H$ or cortisone therapy*

\begin{tabular}{|c|c|c|c|}
\hline Patients & $\begin{array}{l}\text { No. of } \\
\text { pts. }\end{array}$ & $\begin{array}{c}\text { Leukocyte } \\
\text { lysate, } 1: 10 \\
\text { in watert }\end{array}$ & $\begin{array}{l}\text { Plasma, } \\
1: 10 \text { in } \\
\text { saline }\end{array}$ \\
\hline $\begin{array}{l}\text { A. Controls (no steroid Rx) } \\
\text { On i.v. ACTH } \\
\text { Comparison of data }\left\{\begin{array}{l}t \\
p\end{array}\right.\end{array}$ & $\begin{array}{r}26 \\
8\end{array}$ & $\begin{array}{c}41.6 \pm 11.6 \\
27.2 \pm 13.5 \\
2.437 \\
<0.05\end{array}$ & $\begin{array}{c}20.2 \pm 10.0 \\
12.0 \pm 3.8 \\
1.943 \\
>0.05\end{array}$ \\
\hline $\begin{array}{l}\text { B. Before } R x \\
\text { On high-dosage cortisone } \\
\text { Comparison of data }\left\{\begin{array}{l}t \\
p\end{array}\right.\end{array}$ & $\begin{array}{l}8 \\
8\end{array}$ & $\begin{array}{c}39.6 \pm 10.3 \\
35.9 \pm 11.6 \\
0.675 \\
>0.05\end{array}$ & $\begin{array}{c}27.2 \pm 15.2 \\
16.8 \pm 8.0 \\
1.713 \\
>0.05\end{array}$ \\
\hline $\begin{array}{l}\text { C. Controls (no steroid } \mathrm{Rx} \text { ) } \\
\text { On maintenance cortisone } \\
\text { Comparison of data }\left\{\begin{array}{l}\mathrm{t} \\
\mathrm{p}\end{array}\right.\end{array}$ & $\begin{array}{r}26 \\
7\end{array}$ & $\begin{array}{c}41.6 \pm 11.6 \\
34.6 \pm 16.4 \\
0.689 \\
>0.05\end{array}$ & $\begin{array}{c}20.2 \pm 10.0 \\
17.4 \pm 6.9 \\
0.719 \\
>0.05\end{array}$ \\
\hline
\end{tabular}

* Data represent per cent (土S.D.) lysis of lysozyme substrate by the test material.

† Corrected for plasma residue (see Text, Experimental Procedure).

posure of leukocytes to adrenocorticosteroids was interpreted as evidence of protection of the cells from injury.

Leukocyte lysate titres were determined as described previously (18) using a 1:10 dilution of the lysate for titration. The titres represent the maximal amount of lysozyme which is released from leukocytes on exposure of the cells to distilled water.

Plasma titres of lysozymes were determined, using $1 \mathrm{ml}$. of a 1: 10 dilution of plasma plus $1.5 \mathrm{ml}$. of lysozyme substrate. The lysozyme activity of plasma is a factor of importance in the present study because of the trace of plasma residue left on the leukocytes in the method used. The method avoids all excess handling of the leukocytes, either for purposes of washing them or for measuring plasma residues. Where comparisons were made between in vitro treated and untreated leukocytes, as in Table II, no error was introduced, since all of the leukocytes were from the same suspension with the same plasma contamination. However, where comparisons were drawn between leukocytes obtained from the patient before and after treatment with steroids, an error was introduced which tends to increase the difference between the observations before and after therapy. This occurred because, with the marked rise in leukocyte count which appeared during therapy, final dilution of any plasma residue became proportionally high as counts were adjusted to 11,000 per cmm. Also, plasma titres of lysozyme tended to decrease with therapy. It is apparent, therefore, that a correction must be made for plasma lysozyme activity ${ }^{8}$

which are reported in detail elsewhere (16-18), an increased titre of lysozyme in the medium in which the cells are suspended is interpreted as one index of cellular injury.

8 A control experiment was run, in which the plasmaplatelet-dextran supernate was removed by suction from ten identical tubes of centrifuged leukocytes, using the same technique as was used throughout the experiments presented here. The plasma residue was then carefully before any valid comparison can be made. For all comparisons before and after treatment of the patient (Tables I and II, Figures 1 and 2), therefore, only those patients were included on whom complete data were at hand concerning individual plasma lysozyme titres and final volume of leukocytes after dilution to 11,000 per $\mathrm{cmm}$. With these data and the mean plasma residue, ${ }^{8}$ correction through the possible range of lysozyme activity due to plasma contamination could be made for both leukocytes and leukocyte lysates.

In Table I-A and -B, the activity of the mean plasma residue +2 S.D. (or $0.1734 \mathrm{ml}$.) was deducted from the control or baseline observations, whereas the mean plasma residue -2 S.D. (or zero) was deducted from the observations after therapy. Thus, the difference in the levels before and after therapy was minimized to the greatest extent that the plasma artefact of the experimental method could have influenced the results, and the significance of the remaining, considerably-lessened difference was then tested. This was not possible in Table I-C, because there was insufficient difference between control and treated patients to permit such an approach to the data. Therefore, the maximum possible deduction for plasma activity was made from both sets of observations in this instance before testing the significance of the difference between observations.9 The same procedure was carried out in preparing the data for Figures 1 and 2.

measured, and the mean residue volume was found to be $0.083 \mathrm{ml}$. \pm 0.0452 (S.D.).

- For example, in Table I-A, column "saline," the uncorrected lysozyme levels were $31.2 \pm 10.5$ and $10.1 \pm 5.5$ for leukocytes from untreated and treated patients, respectively. Following maximum correction for possible plasma residue contamination, the lysozyme levels which were finally used for comparison were $23.6 \pm 9.8$ and $10.1 \pm 5.5$, respectively. In Table $I-C$, column "saline," the uncorrected levels were $31.2 \pm 10.5$ and $29.6 \pm 10.8$, 


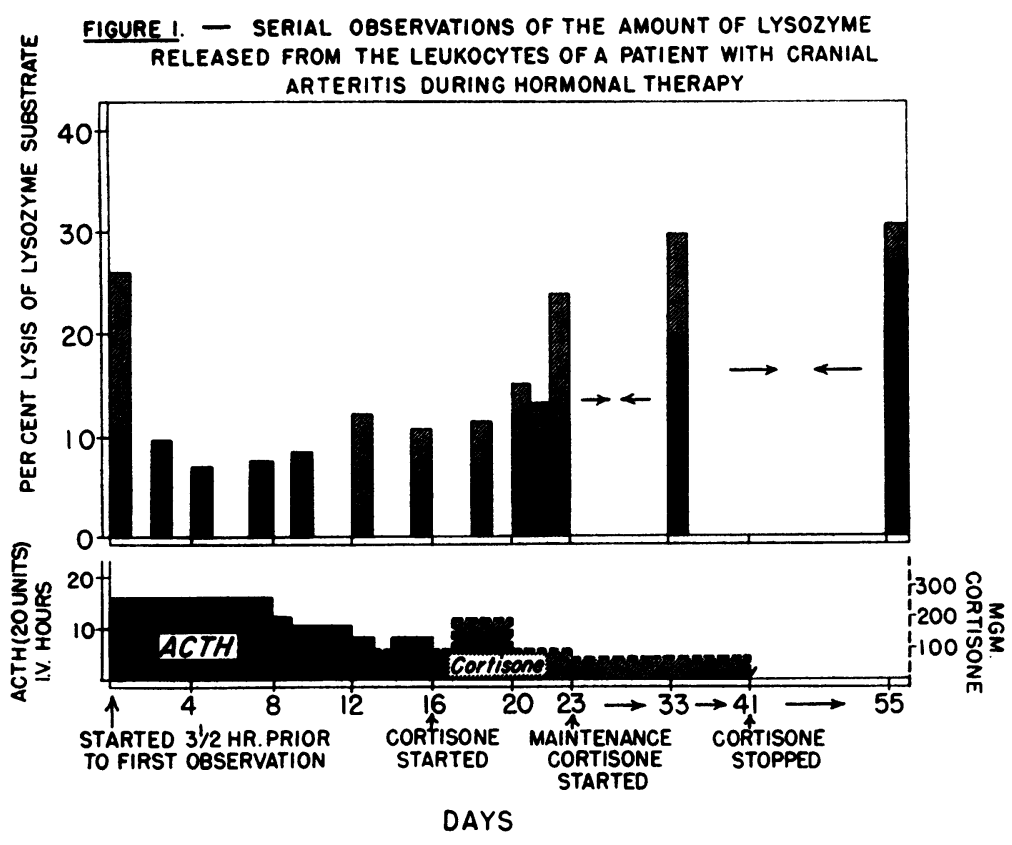

Figure 1

The black bar represents the per cent lysis of lysozyme substrate by leukocytes subjected to the minimal trauma of handling. The cross-hatched bar demonstrates the superimposed cellular injury (expressed as increased release of enzyme) when the same leukocyte suspension was exposed to Piromen in vitro. All observations have been corrected for plasma contamination.

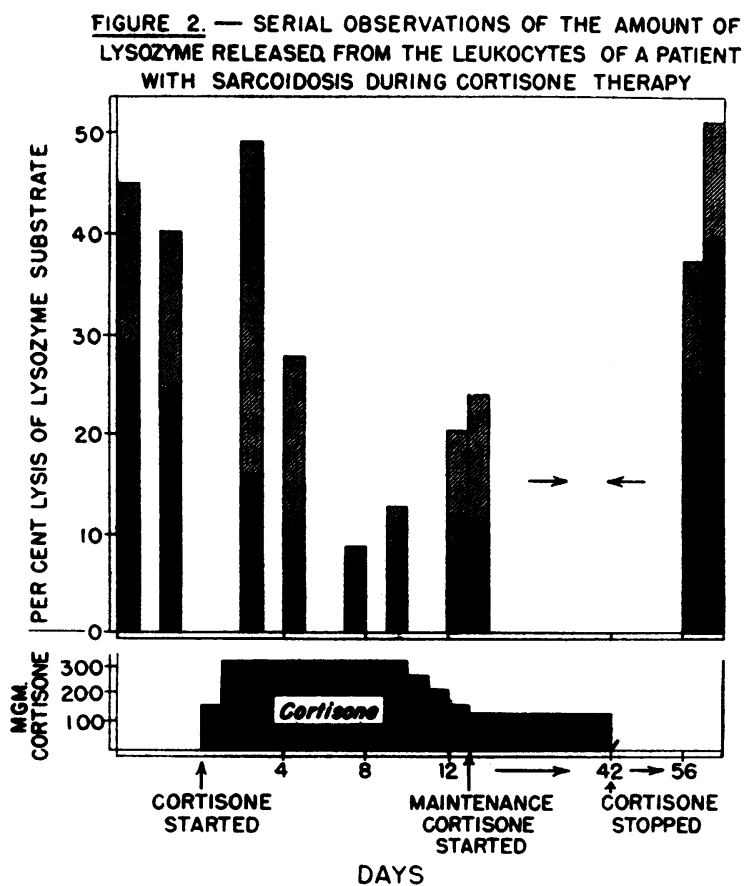

FIGURE 2

Representations by the black and cross-hatched bars are as for Figure 1.

\section{RESULTS}

The results are summarized in Tables I to III. ${ }^{10}$ Serial observations were obtained on most of the patients, in same instances prior to therapy, through intravenous ACTH or high-dosage oral cortisone to maintenance cortisone or no therapy. This is graphically illustrated in Figures 1 and 2 for two patients treated with intravenous ACTH and oral cortisone, respectively. All patients showed the same trend, although not all to the same degree as illustrated by these two patients, as is evident from the mean values recorded in the tables.

respectively; after correction they were $23.6 \pm 9.8$ and $20.5 \pm 7.1$, respectively.

10 Five patients were given a single four-hour intravenous infusion of $100 \mathrm{mg}$. of hydrocortisone (free alcohol) Merck in 5 per cent dextrose in water. Observations were made prior to and after the infusion (immediately after, at four hours and at 24 hours). A trend toward a decrease in susceptibility of the patient's leukocytes to injury was observed, disappearing after 24 hours. However, this did not occur in all of the patients, and the overall significance of the trend could not be adequately evaluated in the small series. For this reason, the data are not included in the present report. 
TABLE III

Effect of exposure of leukocytes from steroid-treated and untreated humans to in vitro hydrocortisone and Piromen

\begin{tabular}{|c|c|c|c|c|c|}
\hline & \multicolumn{5}{|c|}{$\begin{array}{l}\text { Mean difference ( }(\text { S.D.) in lysozyme activity between a leukocyte suspension and the same } \\
\text { suspension exposed in vitro as indicated byt }\end{array}$} \\
\hline & *(1) & (2) & (3) & (4a) & (4b) \\
\hline No. of Pts. & 39 & 11 & 8 & 8 & 8 \\
\hline $\begin{array}{c}(\mathrm{A}) \dagger \\
\mathrm{t} \\
\mathrm{p}\end{array}$ & $\begin{array}{c}+16.8 \pm 7.6 \\
13.79 \\
<0.01\end{array}$ & $\begin{array}{c}+17.0 \pm 5.3 \\
10.70 \\
<0.01\end{array}$ & $\begin{array}{c}+7.9 \pm 4.3 \\
5.172 \\
<0.01\end{array}$ & $\begin{array}{c}+14.2 \pm 2.4 \\
17.04 \\
<0.01\end{array}$ & $\begin{array}{c}+8.3 \pm 3.4 \\
6.918 \\
<0.01\end{array}$ \\
\hline $\begin{array}{c}(B) \dagger \\
t \\
p\end{array}$ & $\begin{array}{c}-6.2 \pm 4.9 \\
7.982 \\
<0.01\end{array}$ & $\begin{array}{c}-3.9 \pm 3.6 \\
3.407 \\
<0.01\end{array}$ & $\begin{array}{c}-1.8 \pm 1.7 \\
2.887 \\
<0.05\end{array}$ & $\begin{array}{c}-6.5 \pm 2.5 \\
7.303 \\
<0.01\end{array}$ & $\begin{array}{c}-2.4 \pm 2.5 \\
2.685 \\
<0.05\end{array}$ \\
\hline $\begin{array}{c}(C) t \\
t \\
p\end{array}$ & $\begin{array}{c}+6.2 \pm 6.7 \\
5.771 \\
<0.01\end{array}$ & $\begin{array}{c}+6.7 \pm 5.1 \\
4.337 \\
<0.01\end{array}$ & $\begin{array}{c}+3.8 \pm 3.3 \\
3.250 \\
<0.02\end{array}$ & $\begin{array}{c}+4.2 \pm 3.8 \\
3.102 \\
<0.02\end{array}$ & $\begin{array}{c}+1.2 \pm 3.7 \\
0.887 \\
>0.05\end{array}$ \\
\hline
\end{tabular}

* (1) Untreated patients.

(2) Patients receiving maintenance oral cortisone.

(3) Patients receiving i.v. ACTH.

(4) Patients receiving large dosage oral cortisone.

(a) Before therapy.

(b) After 7-9 days of therapy.

† A. Damaging effect of in vitro exposure of leukocytes to PS Piromen.

B. Protective effect of in vitro exposure of leukocytes to hydrocortisone.

C. Combined effect of in vitro exposure of leukocytes to hydrocortisone and Piromen.

\section{DISCUSSION}

The studies presented here indicate that the leukocytes of patients undergoing treatment with ACTH or cortisone are significantly altered in their response to at least two forms of injury (i.e., mechanical trauma and exposure to a bacterial polysaccharide derived from $P$ s. aeruginosa). This alteration persists and is demonstrable when the leukocyte is removed from the host and isolated from the homeostatic influences which might be contributing to any observed alteration. Lessened susceptibility to injury as indicated by lysozyme activity does not coincide with the disappearance of eosinophils but usually makes its appearance later, sometimes becoming maximal after as long as seven to nine days of treatment. It occurs only with high-dosage hormonal therapy over an adequate period of time. Leukocytes revert to normal when hormonal therapy is discontinued or when maintenance dosage is instituted. When such patients are again treated with large doses of hormones (because of clinical relapse), the leukocytes again tend to show resistance to injury, suggesting that the reversion to normal observed during maintenance therapy is not part of a homeostatic adjustment by the cell but rather a question of size of dose of adrenocorticosteroids.

The same lessened susceptibility to injury can be induced in leukocytes of patients who have received no hormonal therapy by exposing the cells to cortisone or hydrocortisone in vitro. When the leukocytes are obtained from treated patients, such a protective effect in vitro can also be demonstrated, but it is less in degree than in the untreated group. This suggests that there may be a limit to the degree of protection which can be bestowed and that in cells partially altered in this regard in vivo, the additional protection possible by in vitro measures is limited.

Since the method used here for detection of injury to the cell depends on the measurement of a substance (lysozyme) released from the cell into the surrounding medium, it becomes pertinent to inquire whether the substance measured might be absolutely decreased in the cell while the host was being treated with ACTH or cortisone. For this reason, the lysozyme activity of water-lysed leukocytes was measured at the same time that the intact leukocytes were studied. There was no evidence of decreased lysozyme content in the leukocytes of patients treated with cortisone, either in maintenance or high dosage. However, in the leukocytes of patients receiving intravenous $\mathrm{ACTH}$, there was a decrease in demonstrable lysozyme, and the magnitude of the decrease was of possible significance, statistically. 
It seems likely that the observed effects reflect an alteration in the metabolism of the leukocyte which persists during the life of the cell after it has been removed from the host. This concept is supported by the studies of Martin, Chaudhuri, Green, and McKinney (13), Huisman (14), and Layton (15), who have described specific alterations in metabolic processes of tissues exposed in vitro to cortisone. The present studies suggest that some metabolic changes do not depend on influences other than the hormone itself, because essentially the same effect observed in leukocytes from patients receiving ACTH or cortisone therapy could be induced in normal leukocytes by exposure of the cells to cortisone or hydrocortisone in vitro. Indeed, the observed changes may be opposed by other influences in vivo, since it is evident that the hormonal effect on leukocytes was achieved much more rapidly in vitro than in vivo. On the other hand, the effect in vivo, once fully developed, exceeded that obtained in vitro, ${ }^{11}$ despite the fact that the hormonal level in vitro was undoubtedly higher than that in the blood of the treated patient.

It is becoming increasingly evident (19) that the intact organism makes adaptations at various levels during the course of adrenocorticosteroid hormonal therapy and that a given response in vivo cannot be interpreted as necessarily due to a direct effect of the hormone administered. The response may be due, wholly or in part, to inhibitory or synergistic substances produced by cells in response to the hormone. In the present study, a direct hormonal effect on the cells was demonstrated when they were exposed to the hormone in vitro. However, this effect occurred within five hours in vitro, whereas a number of days was required for the development of a similar effect when the hormone was administered in vivo. Further investigations will be necessary to determine why these two responses differ.

\section{SUMMARY}

1. By a method which measures release of lysozyme from cells (an index of cellular injury), the effect of adrenocorticosteroids on the suscepti-

11 To 2 possibly significant degree $(p=<0.05)$ with the leukocytes of patients treated with intravenous ACTH but not so $(p=>0.05)$ with the leukocytes of patients receiving cortisone in high dosage. bility of human leukocytes to injury has been investigated.

2. Leukocytes from patients receiving intravenous ACTH or oral cortisone in high dosage released significantly less lysozyme on exposure to injury by mechanical trauma or by a toxic bacterial derivative than did leukocytes from untreated patients. The maximum protective effect of the hormones did not correlate with disappearance of eosinophils and usually required several days for development.

3. Leukocytes from patients on smaller doses of cortisone did not differ from controls in their susceptibility to injury as measured by the release of lysozyme from the cells.

4. Lessened susceptibility to injury could be induced in leukocytes from untreated patients and patients on maintenance cortisone therapy by exposure of the cells in vitro to cortisone or hydrocortisone. The effect was apparent in five to six hours, in contrast to the period of several days necessary for development of a similar effect in vivo.

5. Lysates of leukocytes of patients on highdosage or maintenance cortisone did not differ from controls in their lysozyme content. Lysates of leukocytes of patients receiving intravenous ACTH showed less lysozyme activity than did controls.

\section{REFERENCES}

1. Duke-Elder, S., and Ashton, N., Action of cortisone on tissue reactions of inflammation and repair with special reference to the eye. Brit. J. Ophth., 1951, 35, 695.

2. Rebuck, J. W., and Mellinger, R. C., Interruption by topical cortisone of leukocytic cycles in acute inflammation in man. Ann. New York Acad. Sc., 1953, 56, 715.

3. Thomas, L., Cortisone and infection. Ann. New York Acad. Sc., 1953, 56, 799.

4. Selye, $H$., On the mechanism through which hydrocortisone affects the resistance of tissues to injury. An experimental study with the granuloma pouch technique. J.A.M.A., 1953, 152, 1207.

5. Cook, C., and McDonald, R. K., Effect of cortisone on the permeability of the blood-aqueous barrier to fluorescein. Brit. J. Ophth., 1951, 35, 730.

6. Ashton, N., and Cook, C., In vivo observations of the effects of cortisone upon the blood vessels in rabbit ear chambers. Brit. J. Exper. Path., 1952, 33, 445. 
7. Ebert, R. H., and Barclay, W. R., Changes in connective tissue reaction induced by cortisone. Ann. Int. Med., 1952, 37, 506.

8. Ragan, C., Howes, E. L., Plotz, C. M., Meyer, K., Blunt, J. W., and Lattes, R., The effect of ACTH and cortisone on connective tissue. Bull. New York Acad. Med., 1950, 26, 251.

9. Zoger, S., Observations on the influence of cortisone on tissue response to injury. Yale J. Biol. \& Med., 1952, 25, 202.

10. Shapiro, R., Taylor, B., and Taubenhaus, M., Local effects of cortisone on granulation tissue and the role of denervation and ischemia. Proc. Soc. Exper. Biol. \& Med., 1951, 76, 854.

11. Steen, A. S., Effect of cortisone on tissue cultures. Brit. J. Ophth., 1951, 35, 741.

12. Gerarde, H. W., and Jones, M., The effect of cortisone on collagen synthesis in vitro. J. Biol. Chem., 1953, 201, 553.

13. Martin, S. P., Chaudhuri, S. N., Green, R., and McKinney, G. R., The effect of bacterial products and hormones on human leukocytes. Clin. Research Proc., 1953, 1, 47.
14. Huisman, T. H. J., The influence of large amounts of cortisone acetate upon the "glucose utilization" of the isolated rat diaphragm. Acta Endocrinol., 1953, $13,55$.

15. Layton, L. L., Effect of cortisone upon chondroitin sulfate synthesis by animal tissues. Proc. Soc. Exper. Biol., \& Med., 1951, 76, 596.

16. Kerby, G. P., A method for detection of leukocyte injury based on release of a lysozyme-like enzyme. Proc. Soc. Exper. Biol. \& Med., 1952, 81, 129.

17. Kerby, G. P., Release of enzyme from human leukocytes on damage by bacterial derivatives. Proc. Soc. Exper. Biol. \& Med., 1952, 81, 381.

18. Kerby, G. P., and Chaudhuri, S. N., Plasma levels and the release of a lysozyme-like enzyme from tuberculin-exposed leukocytes of tuberculous and nontuberculous human beings. J. Lab. \& Clin. Med., 1953, 41, 632.

19. Engel, F. L., Some General Considerations Concerning the Role of the Adrenal Cortex in Intermediary Metabolism. Shwartzman, G., Ch. 2, The effect of ACTH and cortisone upon infection and resistance. New York, Columbia University Press. In press.

\section{SPECIAL NOTICE TO SUBSCRIBERS}

Post Offices will no longer forward the Journal when you move.

Please notify The Journal of Clinical Investigation, Business Office, 622 West 168th Street, New York 32, N. Y. at once when you have a change of address, and do not omit the zone number if there is one. 